\title{
Mycobacterium chelonae associated with tumor-like skin and oral masses in farmed Russian sturgeons (Acipenser gueldenstaedtii)
}

\author{
Elisabetta Antuofermo ${ }^{*}$, Antonio Pais ${ }^{2}$, Sara Nuvoli', Udo Hetzel ${ }^{3}$, Giovanni P Burrai ${ }^{1}$, Stefano Rocca', \\ Monica Caffara ${ }^{4}$, Ilaria Giorgi ${ }^{5}$, Claudio Pedron ${ }^{6}$ and Marino Prearo ${ }^{5}$
}

\begin{abstract}
Background: Non-tuberculous mycobacteria responsible for piscine mycobacteriosis usually produce visceral granulomas in both freshwater and marine species. In this study, the first occurrence of Mycobacterium chelonae associated with tumor-like lesions in the Russian sturgeon (Acipenser gueldenstaedtii) is reported. Fifteen sturgeons from an Italian fish farm showing skin and oral cauliflower-like masses were investigated by histopathology, bacterial culture and molecular analyses.

Results: A total of 20 masses different in size located in the mouth and in pectoral and caudal fins (characterized by abundant calcium deposits and by mild to moderate granulomatous inflammation) were observed with a significant different degree of histological severity. All internal organs of the fish were negative for mycobacteria, Ziehl-Neelsen was positive in only one of the oral masses, whereas bacterial and PCR analyses detected the presence of M. chelonae for almost all the skin and oral masses. Based on these results, a calcinosis of dystrophic origin associated with a chronic granulomatous inflammation was considered as a primary diagnosis consequent to tissue injury in areas susceptible to trauma.

Conclusions: We hypothesized that the occurrence of $M$. chelonae in farmed sturgeons was only a secondary event related to its presence in a stressful rearing environment and subsequent to a dystrophic calcinosis occurred in previously damaged tissues.
\end{abstract}

Keywords: Acipenser gueldenstaedtii, Aquaculture, Calcinosis circumscripta, Fish pathology, Mycobacteria

\section{Background}

The Russian sturgeon, Acipenser gueldenstaedtii Brandt \& Ratzeburg, 1833, is an ancient fish native to Black Sea, Sea of Azov and Caspian Sea entering all the main rivers that empty into them [1].This species has both anadromous and freshwater populations: at sea, it occurs in shallow coastal and estuarine zones, while in freshwaters it inhabits the deep parts of large rivers with moderate to swift current [2]. It was introduced throughout Europe and, due to loss of habitat caused by the construction of dams and to overfishing to collect its eggs, it is

\footnotetext{
* Correspondence: eantuofermo@uniss.it

'Department of Veterinary Medicine, University of Sassari, Via Vienna 2, 07100 Sassari, Italy

Full list of author information is available at the end of the article
}

now considered critically endangered although it is a promising species for aquacultural purposes [3-6].

In recent decades, sturgeon farming for meat and caviar production has increased in Europe [7]. Nevertheless, the development of sturgeon aquaculture activities has been frequently accompanied by disease outbreaks, including those unknown prior to farming. Unfortunately, research on the major sturgeons diseases had not received much attention in the past and, therefore, the knowledge on their prevalence, distribution, origin and ecological significance is still fairly limited [8]. Although sturgeons are considered relatively resilient to diseases, several bacterial, viral and parasitic diseases have been reported worldwide [8], including Columnaris disease [9-11], motile Aeromonas septicemia [12-14], yersiniosis [15], pseudomonosis [16],

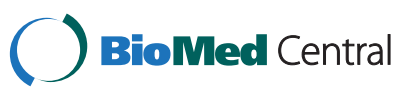


epitheliocystis [17], white sturgeon adenovirus [18,19], herpesvirus [20,21] and iridovirus [22-25].

To date, no reports of skin and/or oral tumor-like masses in sturgeons associated with mycobacterial infections are documented. Only few papers described a group of Siberian sturgeons (Acipenser baeri) imported in Italy from France showing visceral granulomas [26], and caviar fishes from Iran exhibiting gill lesions, both caused by Mycobacterium marinum [27].

The non-tuberculous mycobacteria (NTM), also known as environmental mycobacteria (EM), atypical mycobacteria (AM) and mycobacteria other than tuberculosis (MOTT), include those Mycobacterium species which are not members of the Mycobacterium tuberculosis complex (and M. leprae) [28]. NTM have a worldwide distribution as saprophytes in soil and in treated/untreated waters, where they can remain viable for over 2 years. NTM include many species of acid-fast bacteria, some of which are capable of causing chronic progressive diseases in mammals, birds, reptiles and fish. Thus, infected fish may be considered as primary reservoir for these pathogens and infection is probably acquired from NTM present in the environment by ingesting contaminated food or water containing organic matter, or through gill or skin lesions caused by trauma and parasites [29]. Mycobacteria may cause cutaneous lesions or spread into internal organs through the circulatory or lymphatic systems. Transovarian transmission has also been documented in Siamese fighting fish (Betta splendens) [30]. All fish species should be considered susceptible to mycobacteriosis, with a higher prevalence in farmed animals and significant losses frequently observed in aquacultural activities [31]. However, mycobacteriosis infections and mass mortalities in wild fish is not easy to recognized but see [32], because infected fish die and are easily predated or scavenged.

Disease outbreaks in farmed fish can be related to several management features, such as the quality and quantity of food and water supplied, and the rearing density. As a result, inadequate management could cause abnormal stress associated with a decrease of the normal resistance of the host [30].

Mycobacteriosis in fish is currently attributed to a wide array of species belonging to the Mycobacterium genus, but historically $M$. chelonae, $M$. fortuitum, and M. marinum $[31,33]$ are the most reported species. Furthermore, $M$. marinum is the most common in a wide range of saltwater fish [34] and M. chelonae (M. salmoniphilum) has been identified in different coldwater fish, especially in salmonids [35,36].

In general, piscine mycobacteriosis is a systemic subacute to chronic progressive disease causing grey-whitish nodules (granulomas) and enlargement of various organs (mainly spleen, liver and kidney) [37-39]. Clinical signs are often lacking and hardly detectable until advanced stages, in which cachexia, lordosis, pale gills and skin ulcerative lesions can be seen in some fish species [30]. Skin granuloma caused by NTM infection was not reported in any fish species, except for Atlantic salmon farmed in British Columbia [35].

However, to our knowledge, no skin or oral granulomatous inflammation with excessive mineralization associated with mycobacteria has ever been observed in sturgeons. The aim of this study, therefore, was to describe in detail the first occurrence of tumor-like lesions associated with Mycobacterium chelonae in the Russian sturgeon, Acipenser gueldenstaedtii.

\section{Methods}

\section{Fish sampling}

The study was carried out in a fish farm located in Northern Italy (Ticino basin, Province of Pavia), where several species of sturgeons are reared in raceways system at different density depending on the size of fish. Several juveniles belonging to the same aquaculture production batch ( $<2$ years old) of Acipenser gueldenstaedtii showed skin and oral masses. Fifteen live sturgeons sampled in July 2010 were euthanized by immersion in a lethal dose of tricaine methanesulphonate (MS-222, Sigma-Aldrich), and a complete necropsy of each subject was performed. The sampling was performed in accordance with the Italian Legislative Decree n. 116/1992, in application of the EU Directive 86/609/EEC. For this study, ethical approval from an institutional ethical committee was not required because all the sturgeons examined were collected as a part of a plan of surveillance and sanitary controls on fish health.

The lesions were localized at 3 different levels: oral (lips and cheeks), pectoral, and caudal fins and were categorized according to their size in 3 groups: small (from 0.2 to $<0.5 \mathrm{~cm}$ ), medium (from 0.5 to $2 \mathrm{~cm}$ ) and large (more than $2 \mathrm{~cm}$ ). Furthermore, voluminous skin masses (10 to $20 \mathrm{~cm}$ in diameter) were also observed in older sturgeons (5-6 years old). Due to their high commercial value, these fish were not killed and consequentially their lesions were not evaluated in detail. Furthermore, 10 healthy sturgeons were sampled from the same raceway as negative controls.

\section{Cytopathology and histopathology}

Fine needle aspiration cytology of oral and skin masses were performed and smears were stained with May Grünwald Giemsa (MGG) and Ziehl-Neelsen (ZN). Samples of all lesions were formalin fixed, paraffin embedded and submitted to histopathological evaluation. Slides were stained with Hematoxylin and Eosin (HE), Ziehl-Neelsen (ZN), Von Kossa and Masson's Trichrome stain and observed at light microscopy level. Based on the inflammatory response, mineralization, necrosis and fibroplasia evaluated, 
the histopathological lesions were scored in 3 levels of severity (mild, moderate, and severe) by two different pathologists. Photomicrographs were acquired with a Nikon Digital Sight DS-U1 camera mounted on a Nikon $80-\mathrm{i}$ microscope.

\section{Bacteriological and molecular diagnosis}

Skin and oral lesions as well as visceral organs (spleen, kidney and liver) were collected from each fish. Tissue samples were homogenized, decontaminated using $1.5 \%$ cetylpyridinium chloride (Sigma-Aldrich) for $60 \mathrm{~min}$. and centrifuged at $3000 \mathrm{rpm}$ for $20 \mathrm{~min}$. Tissue homogenates $(10 \mu \mathrm{l})$ were spread onto a glass slide, stained with $\mathrm{ZN}$, and other $10 \mu \mathrm{l}$ cultured on Löwenstein-Jensen media tubes incubated at $25 \pm 1^{\circ} \mathrm{C}$ and $37 \pm 1^{\circ} \mathrm{C}$. Possible mycobacterial growth was assessed every day for a period of 1 month and the isolated colonies were evaluated by growth and biochemical test [40]. Test tubes were maintained for 2-3 months before being considered negative.

Total DNA was extracted from the colony by QIAamp DNA Mini Kit (Qiagen). A fragment of 439 bp of the $65-\mathrm{kDa}$ heat shock protein gene (hsp65) was amplified by two specific primers: Tb11 5'-ACC AAC GAT GGT GTG TCC AT-3' and Tb12 5'-CTT GTC GAA CCG CAT ACC CT-3' [41]. The PCR was carried out in $50 \mu \mathrm{l}$ reactions containing 10X PCR buffer (Invitrogen), $200 \mu \mathrm{M}$ dNTPs (Invitrogen), $0.3 \mu \mathrm{M}$ of each primer, $1.5 \mathrm{mM} \mathrm{MgCl}_{2}$ and 2.5 U Platinum Taq DNA Polymerase (Invitrogen). A Tpersonal (Biometra) thermocycler was used for the amplification with the following parameters: 45 cycles of $1 \mathrm{~min}$ at $94^{\circ} \mathrm{C}, 1 \mathrm{~min}$ at $55^{\circ} \mathrm{C}$ and $1 \mathrm{~min}$ at $72^{\circ} \mathrm{C}$, preceded by 5 min denaturation step at $95^{\circ} \mathrm{C}$ and finished with an extended elongation step at $72^{\circ} \mathrm{C}$ for $10 \mathrm{~min}$. The PCR products were electrophoresed on a $1 \%$ agarose gel (Sigma) stained with SYBR Safe DNA Gel Stain in 0.5X TBE (Molecular Probes-Invitrogen). The PCR product were digested with the restriction enzyme BstEII and HaeIII (MBI Fermentas) following the manufacturer's protocols [41]. Restriction fragments were separated by 3\% agarose gel (Sigma) stained with SYBR Safe DNA Gel Stain in $0.5 \mathrm{X} \mathrm{TBE}$ and the band size were determined by the computer program Quantity One 4.4.1 (Biorad) with $100 \mathrm{bp}$ molecular size standard (XIV Roche). In order to avoid analysis mistake, the digested strains were first separated on the basis of the phenotypic pattern and then electrophoresed together with the specific reference strain (DMSZ 43804/ATCC 35752, Leibniz-Institut, German Collection of Microorganisms and Cell Cultures, Braunschweig, Germany).

\section{Statistical method}

Macroscopical and microscopical features of the lesions were analyzed using Stata 11.2 software (StataCorp LP). Differences between the size of the lesions and their degree of histological severity in the mouth and in pectoral and caudal fins were compared using the nonparametric Kruskal-Wallis test with Dunn's post-hoc comparison [42]. Furthermore, categorical and ordinal variables were compared using the Spearman rho $(\rho)$ rank correlation coefficient. A value of $\rho$ approximately equal to 1 indicates a good correlation, a value near 0 indicates a poor correlation, and a negative value indicates an inverse correlation. A $P$-value $<0.05$ was considered significant.

\section{Results}

\section{Macroscopical findings}

At postmortem examination, a total of 20 skin and oral cavity masses were found in the 15 sturgeons examined. The $73 \%$ of the fish exhibited single lesions, mostly located in the mouth (82\%), although $27 \%$ of the sturgeons showed multiple skin and oral masses. Total skin lesions accounted for $35 \%$, and were located in both pectoral (43\%) and caudal fins (57\%). These lesions were mostly medium-sized (Figure 1A), except for one large (Figure 1B) found in case No. 7 and another small one (case No. 1) located in the pectoral and caudal fins, respectively (Table 1). Grossly, all the skin masses were firm, whitish in color and showed a cauliflower-like exophytic growth (Figure 1A and B). Oral cavity masses (Figure 1C) accounted for $65 \%$ and were significantly larger $(>2 \mathrm{~cm})$ compared to those on the skin (Kruskal-Wallis $\mathrm{H}=12.504, P<0.01$; Dunn's post-hoc test, mouth $v s$ caudal fin $\mathrm{Q}=2.622, P<0.05)$. Oral masses were mostly infiltrative within the submucosa and, on cut section, were composed of a yellowish gritty material (Figure 1D). No one of the sturgeons examined showed visceral lesions.

\section{Cytopathology and histopathology}

Grossly, unstained smears showed a chalky, white material. Cytologically, the aspirate exhibited a large amount of amorphous granular, dark-gray to bluish material admixed with glassy retractile fragments, suggestive of calcium salt deposit, uniformly dispersed in the background. Cellular components were represented by a moderate to severe mixed inflammatory reaction (macrophages, lymphocytes and multinucleated giant cells) and numerous reactive spindloid, fibroblast-like cells. There was no evidence of bacteria or other infectious agents and $\mathrm{ZN}$ was negative for acid-fast bacilli.

On histopathology, skin masses showed generally a multinodular aspect, with an infiltrative growth pattern into the dermis and subcutis, surrounded by abundant fibrous stroma. Only one caudal fin skin mass (case No. 1) exhibited a nodular pattern and was well encapsulated and demarcated (Figure 2A).

Skin lesions were mostly characterized by mild to moderate deposition of amorphous granular calcium material, 

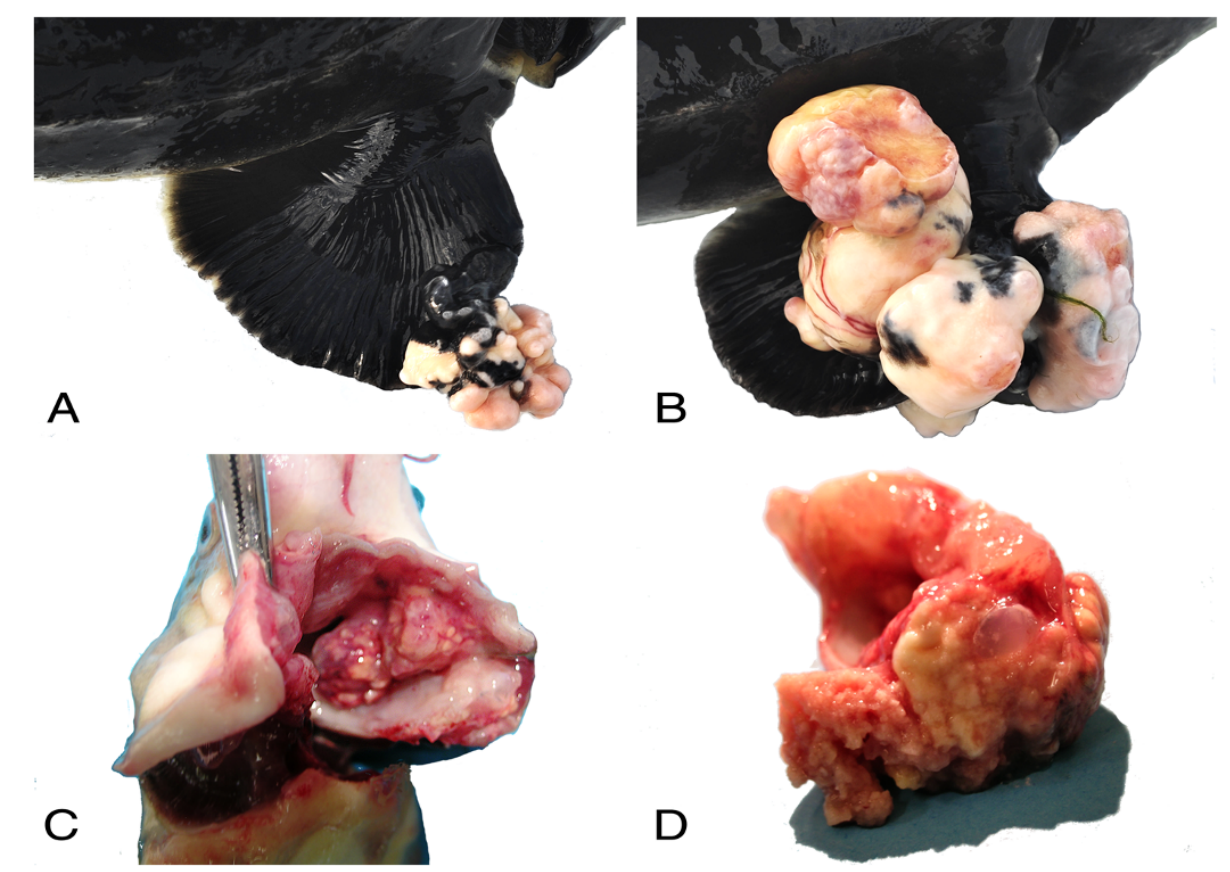

Figure 1 Macroscopic findings. (A) Pectoral fin: multiple cauliflower-like masses of medium size. (B) Pectoral fin: multiple large-sized ulcerated masses. (C) Oral cavity: large-sized lesions infiltrating the submucosa. (D) Detail of the Figure 1C: yellowish pasty component of the lesions.

Table 1 Location and size of oral and skin masses in affected sturgeons

\begin{tabular}{|c|c|c|c|c|c|c|}
\hline Case \# & Lesion \# & Location & Lesion size & Histological severity & $\mathrm{ZN}$ & Culture \\
\hline 1 & 1 & Caudal fin & Small & Mild & Negative & Negative \\
\hline 2 & 1 & Mouth & Medium & Moderate & Negative & Negative \\
\hline 3 & 1 & Mouth & Large & Severe & Positive & Positive \\
\hline \multirow[t]{3}{*}{$4^{a}$} & 1 & Mouth & Large & Severe & Negative & Positive \\
\hline & 2 & Caudal fin & Medium & Moderate & Negative & Negative \\
\hline & 3 & Pectoral fin & Medium & Severe & Negative & Positive \\
\hline 5 & 1 & Pectoral fin & Medium & Severe & Negative & Negative \\
\hline 6 & 1 & Mouth & Large & Severe & Negative & Positive \\
\hline \multirow[t]{2}{*}{$7^{\mathrm{a}}$} & 1 & Mouth & Large & Severe & Negative & Positive \\
\hline & 2 & Pectoral fin & Large & Moderate & Negative & Negative \\
\hline 8 & 1 & Mouth & Large & Severe & Negative & Positive \\
\hline 9 & 1 & Mouth & Large & Severe & Negative & Positive \\
\hline \multirow[t]{2}{*}{$10^{\mathrm{a}}$} & 1 & Mouth & Large & Severe & Negative & Positive \\
\hline & 2 & Caudal fin & Medium & Moderate & Negative & Negative \\
\hline 11 & 1 & Mouth & Large & Severe & Negative & Negative \\
\hline 12 & 1 & Mouth & Large & Severe & Negative & Negative \\
\hline \multirow[t]{2}{*}{$13^{\mathrm{a}}$} & 1 & Mouth & Large & Severe & Negative & Negative \\
\hline & 2 & Pectoral fin & Medium & Moderate & Negative & Negative \\
\hline 14 & 1 & Mouth & Large & Severe & Negative & Negative \\
\hline 15 & 1 & Mouth & Large & Severe & Negative & Negative \\
\hline
\end{tabular}

${ }^{\mathrm{a}}$ Sturgeons with multiple lesions. 


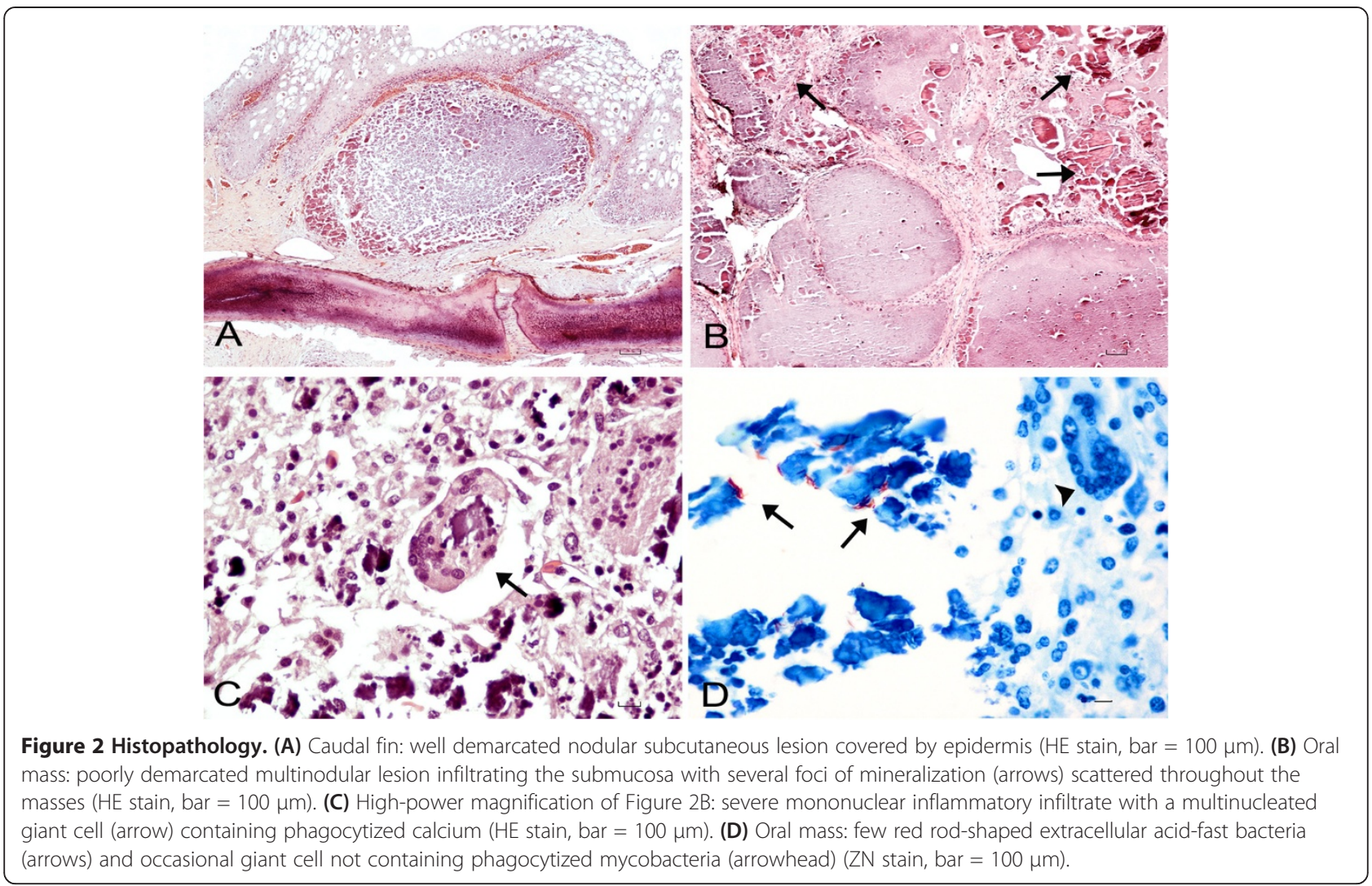

positive to Von Kossa stain, and by mild to moderate inflammations composed mostly of macrophages, lymphocytes, and few giant cells. Mild to moderate fibroplasia was also evident with Masson's Trichrome stain. Oral masses were characterized by a multinodular infiltrative pattern into the submucosa and were poorly demarcated and nonencapsulated (Figure 2B). Moderate to severe inflammatory reaction with a high number of macrophages, lymphocytes and numerous giant cells, phagocytizing calcium debris were found (Figure 2C). Excessive mineralization deposit associated with severe fibroplasia and necrosis was also observed. Red, rod-shaped extracellular acid-fast bacteria within mineralized deposits of calcium and necrotic debris were seen in one of the oral masses (case No. 3) examined (Figure 2D).

Fourteen out of twenty lesions (70\%), mostly found in oral cavity (86\%), exhibited severe histological changes, and showed a higher degree of severity than those located in the skin (Kruskal-Wallis $\mathrm{H}=11.020, P<0.01$; Dunn's post-hoc test, mouth $v s$ caudal fin $\mathrm{Q}=2.578, P<0.05$ ). Spearman correlation analysis found a significant positive correlation only between the size of the lesions and their histopathological severity $(\rho=0.7028, P<0.001)$.

\section{Bacteriological and molecular results}

None of the smears obtained from the masses sampled were positive to $\mathrm{ZN}$ stain. Colonies growth from cultured oral and skin masses, were clearly visible in LöwensteinJensen media tubes showing acid-fast bacilli at $\mathrm{ZN}$ stain (both tubes incubated at $25^{\circ} \mathrm{C}$ and $37^{\circ} \mathrm{C}$ were positive). These colonies were phenotypically and biochemically identified as Mycobacterium chelonae. All the internal organs cultured were negative for mycobacteria. Furthermore, no colony growth of mycobacteria were observed from all negative controls.

All the strains subjected to PCR-RFLP analysis showed a restriction pattern identical to the one of $M$. chelonae (Figures 3 and 4), confirming the results obtained by phenotypic and biochemical identification.

\section{Discussion}

In the present study, the occurrence of Mycobacterium chelonae associated with tumor-like masses with excessive calcium deposition was described for the first time in farmed sturgeons. In general, the presence of this mycobacterium species and its association with gross lesions is considered quite rare in fish, with few reports in the literature. These records described $M$. chelonae mostly associated with granuloma-like visceral nodules in farmed salmon and turbot $[35,43,44]$, in wild perch [45], and also in ornamental fish [39]. Furthermore, M. chelonae was evidenced in several other wild and domestic animals but mostly associated with ulcerative skin lesions [46] and references therein [47]. 


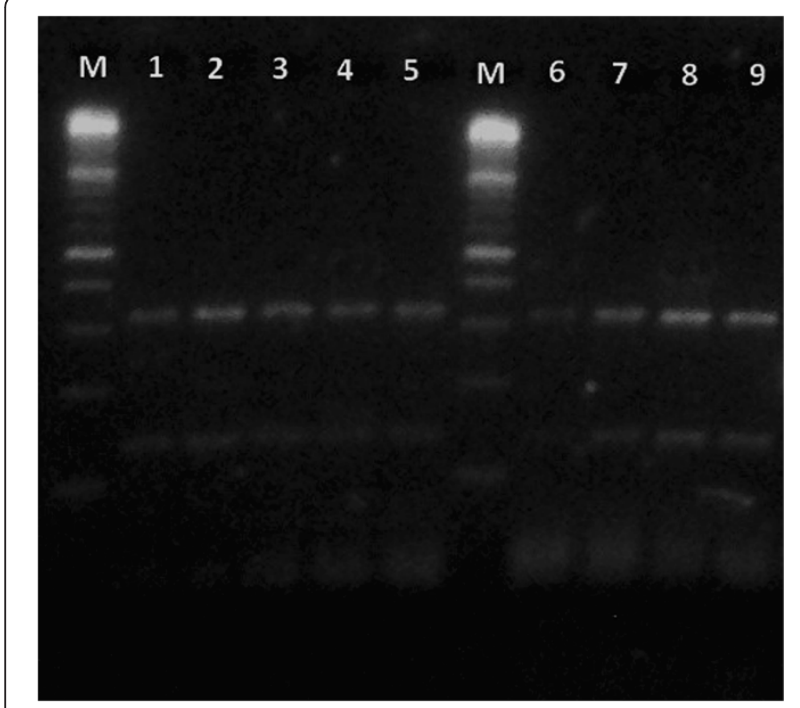

Figure 3 Molecular analysis. BStell enzyme. $M=100$ bp molecular weight standard; lanes 1-8= samples; lane $9=$ reference strain of Mycobacterium chelonae (DMSZ 43804/ATCC 35752).

In all the sturgeons examined in this study, the lesions were different in size and larger masses were mostly observed in the oral cavity, most of which showing a severe histological pattern significantly correlated with their size and with an infiltrative activity. Moreover, all the skin and mouth lesions were characterized by different severity levels of chronic granulomatous inflammation. To the best of our knowledge, granulomatous infiltrates associated with few bacteria, isolated and confirmed by PCR as M. chelonae, were described in salmon [35]. It is

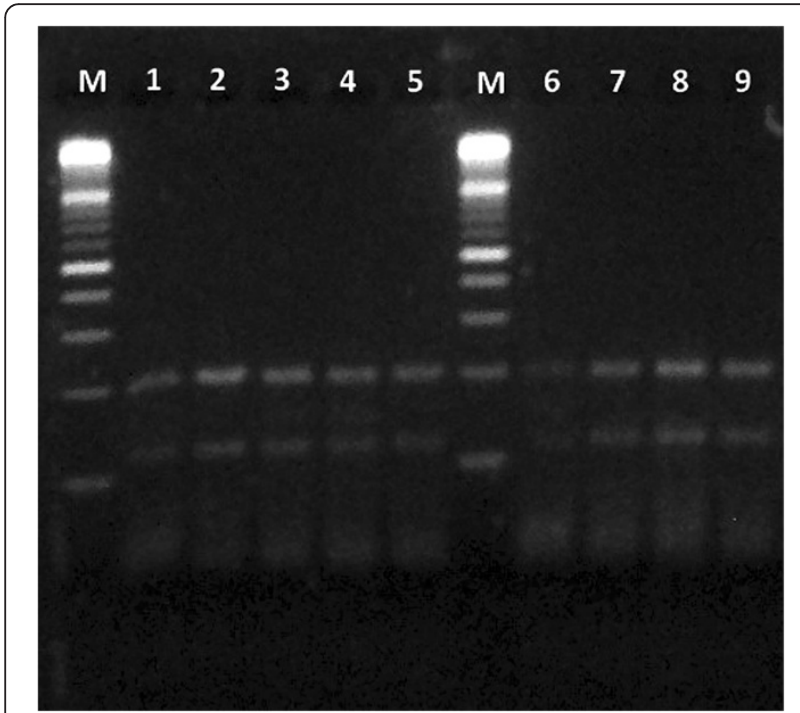

Figure 4 Molecular analysis. Haelll enzyme. $M=100$ bp molecular weight standard; lanes 1-8= samples; lane $9=$ reference strain of Mycobacterium chelonae (DMSZ 43804/ATCC 35752). worth noting that none of the lesions we observed showed typical granulomas, although these structures are quite common in fish organs with mycobacteriosis [31] and references therein. In particular, typical granulomas are characterized by peripheral fibrosis and several layers of epithelioid cells surrounding necrotic areas containing a large amount of acid-fast bacilli $[33,48]$. Conversely, we observed scant $\mathrm{ZN}$ positive bacilli intermingled with abundant mineralization, tissue necrosis and fibroplasia. Strong positivity to Von Kossa stain of mineralized material confirmed that calcium salt deposition was diffusely present within nodular and multinodular masses and increased from smaller to larger lesions. In general, mineralization is rarely encountered in piscine mycobacteriosis [33] and references therein. Nevertheless, ectopic mineralization in soft tissues has been reported for many other fish species [49] and references therein, although different names to describe similar lesions have been used, leading to confusion in terminology. In particular, an ectopic mineralization characterized by tumorlike nodules in subcutaneous tissues containing calcium deposition is defined as Calcinosis circumscripta (CC) [49] and references therein.

Thus, due to the macro and microscopic aspect of the masses we examined (that were all characterized by single or multiple nodules containing abundant calcium deposits), their distribution (single or multiple) and localization (skin and oral mucosa), CC syndrome was considered as a possible diagnosis [49] and references therein. This syndrome is a disorder affecting humans and several animal species (but never described in sturgeons before) and is classified in 3 different forms: metastatic, idiopathic and dystrophic calcinosis [49] and references therein.

Aetiopathogeneses for calcinosis include trauma, foreign body reaction, neoplasms, connective tissue diseases, abscesses, granulomas, inherited disorders and infections [50]. Generally, the ectopic calcified masses consist of hydroxyapatite and amorphous calcium phosphate [51]. It has been hypothesized that the denatured proteins of necrotic cells can serve as a core for ectopic calcification, and that the following degeneration of the collagen fibers and subcutaneous fat tissue can induce the calcification process [51]. In addition, inflammation and fibrosis may be frequently observed as a reaction of calcified deposits (e.g. foreign body reaction).

From a clinical point of view, nodules of calcium deposits can cause skin ulcerations occurring in areas of recurrent microtraumas. Thus, most probably, the calcinosis we observed in the sturgeon masses was of dystrophic origin, because tissue injures especially occurred over body prominences (e.g. pectoral and caudal fins), or in areas susceptible to trauma (e.g. mouth). Probably, therefore, sturgeons affected by these masses can be assumed to have feeding problems, leading to starvation. 
Furthermore, the fact that a number of sturgeons exhibited mouth and skin lesions could be related to farming conditions and, in particular, to stressful breeding density. As a consequence, the mycobacteria observed inside the sturgeon masses could have been present in the rearing environment (i.e. the water) and only after traumatic events infected the fish lesions [31]. Based on this hypothesis, we can suppose that the granulomatous inflammation process could be related to the presence of a foreign body reaction (i.e. the calcium) [49], and the occurrence of $M$. chelonae associated with tumor-like skin and oral lesions was only a secondary event. In fact, this mycobacterium is a fast growing, opportunistic bacillus ubiquitous in nature, exceptionally pathogenic and mainly associated to chronic granulomatous infections in immunocompetent and immunosuppressed subjects [31]. The histological pattern observed in almost all the sturgeon lesions (19 out of 20; $95 \%$ ) seems to confirm this hypothesis, because no acid-fast bacilli were noticed in the macrophages cytoplasm, in epithelioid cells, nor in multinucleated giant cells which contained almost only calcium. Only in one of the oral lesion examined, we found a few extracellular acid-fast bacteria intermixed calcium deposits. However, a number of studies demonstrated that the sensitivity of some piscine mycobacteria to $\mathrm{ZN}$ staining could be referred to their physiological state [52], with acid-fast bacilli easily visible in mature granulomas, but difficult to observe in early lesions [31] and references therein.

For all the above reasons, we are reasonably doubtful in making a definitive diagnosis of mycobacteriosis for the Acipenser gueldenstaedtii specimens examined, although the presence of $M$. chelonae was detected by both tissue cultures and PCR-RFLP analysis. Nevertheless, we may not completely rule out that the lesions we observed could be primarily caused by $M$. chelonae, and a diagnosis of an unusual mycobacteriosis in sturgeons could be made. Thus, the excessive mineralization found in the lesions could be considered the result of a long standing granulomatous inflammation caused by $M$. chelonae. In fact, it could be supposed that sturgeons show an aberrant response to mycobacterial organisms in subcutaneous or mucosal localization leading to a pathological accumulation of calcium in inflammation reaction. Sturgeons, ancient fishes with a mostly cartilaginous endoskeleton, have smaller calcium requirements for calcification than other fish species and deposit significant amounts of calcium in their exoskeleton (i.e. the ganoid scale system and cranium), a feature that is unique to this group of vertebrates [53]. However, although many research efforts have been made in explaining the extracellular matrix calcification (ECM), the pathogenic mechanism causing ectopic deposition of calcium in sturgeon soft tissues remains still unknown [54]. Actually, among a number of molecules involved in the pathways of ectopic mineralization, vitamin K-dependent proteins (VKD) are known to play a important role in this pathogenesis [54].

In particular, a new type of VKD, called Gla-Rich Protein (GRP), which importance in normal and pathological deposition of calcium in tissues is still not completely understood, has been recently isolated in the Adriatic sturgeon, Acipenser naccarii [55].

To our knowledge, this unusual occurrence of $M$. chelonae associated with tumor-like masses with excessive mineralization was never described before in sturgeons and, in general, in fish. It is worth noting that the probability to find mycobacterial infections is higher in farmed fishes than in wild ones, as already pointed out in a recent study for several freshwater species [56]. $M$. chelonae is considered a human pathogen associated with infection of wound in immunocompromised person. However, because the strains of $M$. chelonae grow at different temperature $\left(28.5^{\circ} \mathrm{C}\right.$ or $\left.37^{\circ} \mathrm{C}\right)$, further research is thus needed to definitely clarify the relation between the potential risk of the presence of $M$. chelonae in farmed sturgeons also for people working in aquaculture activities [33,57].

\section{Conclusions}

The presence of Mycobacterium chelonae in skin and oral masses of the farmed specimens of Acipenser gueldenstaedtii reported in this study was considered as a secondary event subsequent to a dystrophic calcinosis occurred in previously damaged tissues. In fact, the absence of typical granulomas in all organs of the fish examined lead us to exclude a primary role of the piscine mycobacteriosis. Finally, experimental in vivo studies will be helpful to clarify the role of $M$. chelonae as a potential pathogen (or opportunistic agent) causing skin and subcutaneous tumor-like masses with calcinosis in sturgeon.

\section{Competing interests}

The authors declare that they have no competing interests.

\section{Authors' contributions}

EA: designed, interpreted macro and microscopic findings and draft the manuscript; AP: performed the statistical analysis and draft the manuscript; $\mathrm{SN}$ : performed and interpreted the cytopathology and histopathology; UH: have been involved in the interpretation of histopathological results and critically revised the manuscript; GPB, SR: performed, interpreted the statistical analysis and prepared figures; IG, MC: performed and interpreted the bacteriological and the molecular analysis; CP: have been involved in the conception of the study and performed fish sampling; MP: designed, coordinated the study and revised the manuscript for important intellectual content. All authors read and approved the final manuscript.

\section{Acknowledgements}

The authors wish to thank Marina A. Sanna, Tiziana Cubeddu (Department of Veterinary Medicine, University of Sassari) and Paola Arsieni (State Veterinary Institute of Piedmont, Liguria and Aosta Valley) for their valuable technical support. 


\section{Author details}

'Department of Veterinary Medicine, University of Sassari, Via Vienna 2, 07100 Sassari, Italy. ${ }^{2}$ Section of Animal Science, Department of Agriculture, University of Sassari, Via Enrico de Nicola 1, 07100 Sassari, Italy. ${ }^{3}$ Department of Veterinary Bioscience, Faculty of Veterinary Medicine, University of Helsinki, Agnes Sjöbergin katu 2, Fl-00014 Helsinki, Finland. 'Department of Veterinary Medical Sciences, Alma Mater Studiorum, University of Bologna, Via Tolara di Sopra 50, 40064 Ozzano Emilia (BO), Italy. ${ }^{5}$ State Veterinary Institute of Piedmont, Liguria and Aosta Valley, Fish Disease Laboratory, Via Bologna 148, 10154 Torino, Italy. ${ }^{6}$ DVM, 20090 Settala, Milano, Italy.

Received: 31 May 2013 Accepted: 6 January 2014

Published: 14 January 2014

\section{References}

1. Sokolov LI, Berdicheskii LS: Acipenseridae. In The Freshwater Fishes of Europe. Vol. 1, Part Ilth edition. Edited by Holcík J. Wiesbaden, Germany: AULA-Verlag; 1989:150-153.

2. Froese R, Pauly D: FishBase. 2012. www.fishbase.org (version 02/2012).

3. Bronzi $P$, Rosenthal $H$, Arlati $G$, Williot $P$ : A brief overview on the status and prospects of sturgeon farming in Western and Central Europe. J Appl Ichthyol 1999, 15:224-227.

4. Celikkale MS, Memis D, Ercan E, Cagiltay F: Growth performance of juvenile Russian sturgeon (Acipenser gueldenstaedtii Brandt \& Ratzenburg, 1833) at two stocking densities in net cages. J App/ Ichthyol 2005, 21:14-18.

5. Kottelat M, Gesner J, Freyhof J: Acipenser gueldenstaedtii. In IUCN Red List of Threatened Species. IUCN 2011. Version 2011.2. 2010. www.iucnredlist.org.

6. Nathanailides C, Tsoumani M, Papazogloy A, Paschos I: Hatching time and post-hatch growth in Russian sturgeon Acipenser gueldenstaedtii. J Appl Ichthyol 2002, 18:651-654.

7. Bronzi $P$, Rosenthal $H$, Gessner J: Global sturgeon aquaculture production: an overview. J Appl Ichthyol 2011, 27:169-175.

8. Bauer ON, Pugachev ON, Voronin VN: Study of parasites and diseases of sturgeons in Russia: a review. J Appl Ichthyol 2002, 18(4-6):420-429.

9. Dottori M, Santi A, Ausini A, Carboni A: Isolation of Flexibacter columnaris from sturgeon (Acipenser transmontanus) with gill disease. Sel Vet 1990, 31:279-284.

10. Karatas S, Ercan D, Steinum TM, Turgay E, Memis D, Candan A: First isolation of a Flavobacterium johnsoniae like bacteria from cultured Russian sturgeon in Turkey. J Anim Vet Adv 2010, 9:1943-1946.

11. Wang L-F, Xie H-X, Zhang J, Li N, Yao W-J, Zhang L-Q, Xiong C-X, Nie P. Columnaris disease and genetic diversity of its bacterial pathogen Flavobacterium columnare in freshwater fish in China. Acta Hydrobiol Sin 2010, 34:367-377.

12. Cao HP, Yang XI, Gao P, Li Y, Zhang SJ, Deng L: Preliminary study of the pathogens isolates from bacterial septicaemia syndrome of sturgeons. Freshw Fisher 2007, 37:53-56

13. Colussi S, Gasparri F, Brunetti R, Ferrari A, Marturano S, Prearo M: Aeromonas hydrophila infection in farmed Siberian sturgeon (Acipenser baeri). Ittiopatologia 2005, 2:105-110.

14. Quaglio F, Bocus R, Delgado ML, Gamberini L, Nobile L, Minelli C, Galuppi R, Restani R: Aeromonas hydrophila in sterlets (Acipenser ruthenus) in Padana plain. Boll Soc It Patol Ittica 2000, 28:17-32.

15. Vuillaume A, Brun R, Chene P, Sochon E, Lesel R: First isolation of Yersinia ruckeri from sturgeon, Acipenser baeri Brandt, in South West of France. Bull Eur Ass Fish Pathol 1987, 7:18-19.

16. Brunetti R, Gasparri F, Marturano S, Prearo M: Pseudomonas fluorescens infection in farmed Siberian sturgeon (Acipenser baeri). Ittiopatologia 2006, 3:221-226.

17. Groff JM, LaPatra SE, Munn RJ, Anderson ML, Osburn BI: Epitheliocystis infection in cultured white sturgeon (Acipenser transmontanus): antigenic and ultrastructural similarities of the causative agent to the chlamydiae. J Vet Diagn Invest 1996, 8:172-180.

18. Hedrick RP, Speas J, Kent ML, Mcdowell T: Adenovirus-Like particles associated with a disease of cultured white sturgeon, AcipenserTransmontanus. Can J Fish Aquat Sci 1985, 42:1321-1325.

19. Kovacs GM, LaPatra SE, D'Halluin JC, Benko M: Phylogenetic analysis of the hexon and protease genes of a fish adenovirus isolated from white sturgeon (Acipenser transmontanus) supports the proposal for a new adenovirus genus. Virus Res 2003, 98:27-34
20. Hedrick RP, Mcdowell TS, Groff JM, Yun S, Wingfield WH: Isolation of an epitheliotropic herpesvirus from white sturgeon Acipenser-Transmontanus. Dis Aquat Organ 1991, 11:49-56.

21. Watson LR, Yun SC, Groff JM, Hedrick RP: Characteristics and pathogenicity of a novel herpesvirus isolated from adult and subadult white sturgeon Acipenser-Transmontanus. Dis Aquat Organ 1995, 22:199-210.

22. Adkinson MA, Cambre M, Hedrick RP: Identification of an iridovirus in Russian sturgeon (Acipenser gueldenstaedtii) from Northern Europe. Bull Eur Ass 1998, 18:29-32.

23. Hedrick RP, Groff JM, Mcdowell T, Wingfield WH: An iridovirus infection of the integument of the white sturgeon Acipenser transmontanus. Dis Aquat Organ 1990, 8:39-44.

24. Lapatra SE, Groff JM, Jones GR, Munn B, Patterson TL, Holt RA, Hauck AK, Hedrick RP: Occurrence of white sturgeon iridovirus infections among cultured white sturgeon in the Pacific-Northwest. Aquaculture 1994, 126:201-210.

25. Raverty S, Hedrick R, Henry J, Saksida S: Diagnosis of sturgeon iridovirus infection in farmed white sturgeon in British Columbia. Can Vet J 2003, 44:327-328.

26. Manfrin A, Prearo M, Alborali L, Salogni C, Ghittino C, Fioravanti ML: Mycobacteriosis in sea bass, rainbow trout, striped bass and Siberian sturgeon in Italy. In Program, abstracts and report of EAFP Workshop "Zoonotic infections from fish and shellfish": 14-19 September 2009. Prague, Czech Republic; 2009:5

27. Ghaemi EO, Ghazesaeed K, Nasab FF, Hashemzade Z, Vatani S, Mohamedi M, Mansourian AR: Mycobacterium marinum infection in caviar fishes and fisherman's in a Caspian Sea province in North of Iran. J Biol Sci 2006, 6:1150-1152.

28. Primm TP, Lucero CA, Falkinham JO: Health impacts of environmental mycobacteria. Clin Microbiol Rev 2004, 17:98-106.

29. Beran V, Matlova L, Dvorska L, Svastova P, Pavlik I: Distribution of mycobacteria in clinically healthy ornamental fish and their aquarium environment. J Fish Dis 2006, 29(7):383-393.

30. Chinabut S: Mycobacteriosis and nocardiosis. In Fish diseases and disorders. Edited by Woo PTK, Bruno DW. UK: CABI Publishing; 1999:319-340. 2nd Vol. 3: Viral, bacterial and fungal infections.

31. Gauthier DT, Rhodes MW: Mycobacteriosis in fish: a review. Vet J 2009, 180:33-47

32. Gauthier DT, Latour RJ, Heisey DM, Bonzek CF, Gartland J, Burge EJ, Vogelbein WK: Mycobacteriosis-associated mortality in wild striped bass (Morone saxatilis) from Chesapeake Bay. U.S.A. Ecol Appl 2008, 18:1718-1727.

33. Decostere A, Hermans K, Haesebrouck F: Piscine mycobacteriosis: a literature review covering the agent and the disease it causes in fish and humans. Vet Microbiol 2004, 99:159-166.

34. Jacobs JM, Stine CB, Baya AM, Kent ML: A review of mycobacteriosis in marine fish. J Fish Dis 2009, 32:119-130.

35. Brocklebank J, Raverty S, Robinson J: Mycobacteriosis in Atlantic salmon farmed in British Columbia. Can Vet J 2003, 44(6):486-489.

36. Whipps CM, Butler WR, Pourahmad F, Watral VG, Kent ML: Molecula systematics support the revival of Mycobacterium salmoniphilum (ex Ross 1960) sp nov., nom. rev., a species closely related to Mycobacterium chelonae. Int J Syst Evol Micr 2007, 57:2525-2531.

37. Ghittino P: Infezione da batteri acido resistenti. In Tecnologia e patologia in acquacoltura. Edited by Ghittino P. Tipografia Emilio Bono, Italy: Torino; 1985:111-112. Vol. 2: Patologia.

38. Prearo M, Zanoni RG, Dall'Orto BC, Pavoletti E, Florio D, Penati V, Ghittino C: Mycobacterioses: emerging pathologies in aquarium fish. Vet Res Commun 2004, 28:315-317.

39. Zanoni RG, Florio D, Fioravanti ML, Rossi M, Prearo M: Occurrence of Mycobacterium spp. in ornamental fish in Italy. J Fish Dis 2008, 31:433-441.

40. Kent TP, Kubica PG: Public health mycobacteriology: a guide for the level III laboratory. Atlanta, Georgia: U.S. Department of Health and Human Services, Public Health Service, Centre for Diseases Control; 1985

41. Telenti A, Marchesi F, Balz M, Bally F, Bottger EC, Bodmer T: Rapid identification of mycobacteria to the species level by polymerase chain-reaction and restriction enzyme analysis. J Clin Microbiol 1993 31:175-178.

42. Zar JH: Biostatistical analysis. 5th edition. Upper Saddle River, New Jersey: Prentice-Hall; 2009

43. Bruno DW, Griffiths J, Mitchell CG, Wood BP, Fletcher ZJ, Drobniewski FA, Hastings TS: Pathology attributed to Mycobacterium chelonae infection 
among farmed and laboratory-infected Atlantic salmon Salmo salar. Dis Aquat Organ 1998, 33:101-109.

44. Dos Santos NMS, do Vale A, Sousa MJ, Silva MT: Mycobacterial infection in farmed turbot Scophthalmus maximus. Dis Aquat Organ 2002, 52:87-91.

45. Daoust PY, Larson BE, Johnson GR: Mycobacteriosis in Yellow Perch (Perca-Flavescens) from 2 lakes in Alberta. J Wildlife Dis 1989, 25:31-37.

46. Bercovier $\mathrm{H}$, Vincent $\mathrm{V}$ : Mycobacterial infections in domestic and wild animals due to Mycobacterium marinum, $M$-fortuitum, $M$-chelonae, M-porcinum, M-farcinogenes, M-smegmatis, M-scrofulaceum. M-xenopi, M-kansasii, M-simiae and M-genavense. Rev Sci Tech Oie 2001, 20(1):265-290.

47. Green SL, Lifland BD, Bouley DM, Brown BA, Wallace RJ, Ferrell JE: Disease attributed to Mycobacterium chelonae in South African clawed frogs (Xenopus laevis). Comparative Med 2000, 50:675-679.

48. Astrofsky KM, Schrenzel MD, Bullis RA, Smolowitz RM, Fox JG: Diagnosis and management of atypical Mycobacterium spp. infections in established laboratory zebrafish (Brachydanio rerio) facilities. Comparative Med 2000, 50:666-672.

49. Jubb KVF, Kennedy PC, Palmer's NC: Pathology of domestic animals. 5th edition. Philadelphia: Saunders Elsevier; 2007

50. Łojszczyk-Szczepaniak A, Orzelski M, Śmiech A: Canine calcinosis circumscripta retrospective studies. Medycyna Wet 2008, 64:1397-1400.

51. Reiter N, El-Shabrawi L, Leinweber B, Berghold A, Aberer E: Calcinosis cutis Part I. Diagnostic pathway. J Am Acad Dermatol 2011, 65:1-12.

52. Zerihun MA, Colquhoun DJ, Poppe TT: Experimental mycobacteriosis in Atlantic cod, Gadus morhua L. J Fish Dis 2012, 35:365-377.

53. Fuentes J, Haond C, Guerreiro PM, Silva N, Power DM, Canario AV: Regulation of calcium balance in the sturgeon Acipenser naccarii: a role for PTHrP. Am J Physiol Regul Integr Comp Physiol 2007, 293:R884-R893.

54. Viegas CSB, Cavaco S, Neves PL, Ferreira A, Joao A, Williamson MK, Price PA, Cancela ML, Simes DC: Gla-Rich protein is a novel vitamin k-dependent protein present in serum that accumulates at sites of pathological calcifications. Am J Pathol 2009, 175:2288-2298

55. Viegas CSB, Simes DC, Laize V, Williamson MK, Price PA, Cancela ML: Gla-rich Protein (GRP), a new vitamin k-dependent protein identified from sturgeon cartilage and highly conserved in vertebrates. J Biol Chem 2008, 283:36655-36664.

56. Mrlik V, Slany M, Kubecka J, Seda J, Necas A, Babak V, Slana I, Kriz P, Pavlik I: A low prevalence of mycobacteria in freshwater fish from water reservoirs, ponds and farms. J Fish Dis 2012, 35:497-504.

57. Harriff MJ, Wu M, Kent ML, Bermudez LE: Species of environmental mycobacteria differ in their abilities to grow in human, mouse, and carp macrophages and with regard to the presence of mycobacterial virulence genes, as observed by DNA microarray hybridization. Appl Environ Microb 2008, 74(1):275-285.

doi:10.1186/1746-6148-10-18

Cite this article as: Antuofermo et al: Mycobacterium chelonae associated with tumor-like skin and oral masses in farmed Russian sturgeons (Acipenser gueldenstaedtii). BMC Veterinary Research 2014 10:18.

\section{Submit your next manuscript to BioMed Central and take full advantage of:}

- Convenient online submission

- Thorough peer review

- No space constraints or color figure charges

- Immediate publication on acceptance

- Inclusion in PubMed, CAS, Scopus and Google Scholar

- Research which is freely available for redistribution 